\title{
LA INCIDENCIA DE LOS MEDIOS DE COMUNICACIÓN EN LA PRESUNCIÓN DE INOCENCIA ${ }^{1}$
}

\author{
Nadya García YéPEZ ${ }^{2}$ \\ UNIVERSIDAD DE SALAMANCA - ESPAÑA
}

\section{RESUMEN:}

Los medios de comunicación desempeñan una función importante que es la de difundir información, son los encargados de crear la opinión pública y, por ende, su influencia es determinante en la sociedad; para ello, se fundamentan en el derecho a la libertad de información, pero ¿qué pasa si este derecho colisiona con otros, también fundamentales, como el de la presunción de inocencia? Cuando los medios de comunicación, en el ejercicio de sus actividades, difunden información acerca de procesos penales, que se están llevando a cabo en la administración de justicia, un mal manejo de la información podría implicar serias vulneraciones al debido proceso.

\section{PALABRAS ClAVES:}

Presunción de inocencia, medios de comunicación, juicios paralelos, debido proceso, opinión pública

1 Artículo recibido el 29 de octubre de 2019 y aprobado el 24 de noviembre de 2019

2 Investigadora y Doctoranda en la Universidad de Salamanca ORCID: 0000-0003-4444-3818 


\section{ABSTRACT:}

The media play an important role that is to disseminate information, they are responsible for creating public opinion and, therefore, their influence is decisive in society, to do this, they are based on the right to freedom of information, but what happens if this right collides with others, also fundamental, such as the presumption of innocence? When the media, in the exercise of its activities, disseminate information about criminal proceedings, which are being carried out in the administration of justice, mishandling of information could imply serious violations of due process.

\section{KEYWORDS:}

Presumption of innocence, media, parallel trials, due process, public opinion 


\section{LA INCIDENCIA DE LOS MEDIOS DE COMUNICACIÓN EN LA PRESUNCIÓN DE INOCENCIA}

\section{Presunción de inocencia}

\section{1. Definición}

La presunción de inocencia es una garantía básica y vertebral de todo proceso penal, en la que se establece que aquella persona que ha sido investigada y/o procesada penalmente, debe ser tratada como inocente, durante el transcurso de todas las etapas del juicio y previas a él hasta que no se dicte la sentencia condenatoria y ésta se encuentre firme; por ende, este principio reconoce como regla general el derecho del procesado (o investigado) a permanecer en libertad durante el proceso penal; este principio rector, además, sirve para limitar las medidas del ejercicio del ius puniendi -Derecho penal o Derecho a sancionar-, traduciéndose éste como una garantía de los ciudadanos frente al poder punitivo del Estado ${ }^{3}$.

3 GARCíA, J. El principio procesal de inocencia en el COIP, Derecho Ecuador. 2014, párr. 9 y ss. (versión digital) En el mismo sentido, CORDÓN, J. Prueba indiciaria y presunción de inocencia en el proceso penal. Madrid, Instituto Vasco de Derecho Procesal, 2012, p. 83. 
Si se parte de un desglose de los términos que lo conforman, se debe desarrollar el término presunción y en tal sentido, se debe mencionar que se trata de una presunción ${ }^{4}$ iuris tatum, es decir, aquella ficción jurídica establecida por Ley, mediante la cual se da por cierto un determinado hecho o acontecimiento, sin perjuicio que se pueda demostrar lo contrario; por tanto, la presunción de inocencia admite prueba en contra, siempre y cuando esté desarrollada con las garantías establecidas, como ya se mencionará en los siguientes párrafos.

Por el otro lado, se debe entender la inocencia como la ausencia de responsabilidad de un sujeto en una ofensa o hecho específico ${ }^{5}$; si nos remitimos a CABANELLAS ${ }^{6}$, se encuentra una definición similar: falta de culpa o equivocada calificación en tal sentido, el vocablo inocencia etimológicamente proviene del latín innocens, en el cual in es una negación y nocere es producir un daño, por lo tanto, algo inocente es lo que no es destructivo, ni dañino 7 ; además, este concepto también está muy vinculado a la perspectiva religiosa, pues si se busca en cualquier diccionario básico, se encontrará, entre las definiciones, la falta de culpabilidad sobre el cometimiento de un pecado.

4 Frente a este carácter de presunción, se afirma que, desde el punto de vista técnico, no se trata de una presunción, ni siquiera iuris tatum, sino que se trata de una verdad interina y provisional, que puede ser desvirtuada por la actividad probatoria. ORTEGO, F. La delimitación entre el principio «in dubio pro reo» y la presunción de inocencia en el proceso penal español. Revista Chilena de Derecho y Ciencia Política. vol. 4, N. ${ }^{\circ}$ 3, 2013, p. 24.

5 García Falconí, R. Código Orgánico Integral Penal Comentado. Quito, Latitud Cero, 2014, p. 85.

6 Cabanellas, G. Diccionario Jurídico Elemental. 18. ${ }^{a}$ Santa Fe de Bogotá, Heliasta, 2006, p. 200.

7 Definición de la página DeConceptos.com. Disponible en la siguiente página web: https://deconceptos.com/general/ inocencia. 
En cuanto a la naturaleza jurídica, los autores Yon Ruesta y SÁNCHEZ MÁLAGA ${ }^{8}$ afirman que por el desarrollo que ha tenido, desde su positivización, en la mayoría de las constituciones, y por la importancia dentro del proceso penal, a la presunción de inocencia se la debe entender en un triple sentido: principio, garantía y derecho; asímismo, estos autores parten de la estrecha relación, entre el principio de inocencia y la dignidad humana, puesto que mantener su condición de inocente es una forma de creer y respetarlo como ser humano. La presunción de inocencia es un principio que orienta ${ }^{9}$ y da pautas al juez para que desde el inicio del proceso hasta su fin, evite ser influenciado por el prejuicio social de culpabilidad sobre el procesado y pueda ejercer su actividad de forma imparcial.

\section{2. Origen del Principio de Inocencia}

No existe un criterio único sobre su origen, sin embargo autores, como GARCÍA FALCONí, aseguran que la presunción de inocencia estuvo presente desde los inicios de la humanidad y se ha mantenido a lo largo del desarrollo de ésta, es decir, se reconoce antecedentes, tanto en la descrita, como, posteriormente en la presunción de bondad $^{10}$-en el sistema inquisitivo-, aunque respecto a esta última, se hayan evidenciado algunas posiciones

8 Yon, R., y SÁnchez, A. "Presunción de Inocencia y Estado de Derecho", Revista de Derecho. Editorial TEMIS, N. ${ }^{\circ}$ 51, 2005, p. 145.

9 Sobre este punto, NiEva, J. afirma que: [...] el simple hecho de señalar a una persona como sospechosa genera automáticamente un recelo social ante ese individuo (p. 5). NievA, J. “La razón de ser de la presunción de inocencia", InDret: Revista para el análisis del Derecho. N. ${ }^{\circ}$ 1, 2016, pp. 14-17.

10 Parte de la premisa que los seres humanos tienen cualidades y atributos de ser buenos. 
contrarias, que se fundamentaban no en la bondad de los hombres, sino que se debía presumir la maldad, partiendo de tesis como el pecado original ${ }^{11}$.

En la línea de lo antes mencionado, se puede considerar como antecedente el Código de Hammurabi, pese a que esta primera manifestación es bastante arcaica, este código, en su Ley I, establecía la posibilidad de dar muerte a aquella persona que acusó de asesinato y no pudo comprobarlo; en el Derecho romano, ULPIANO sentó un claro precedente, respecto a este principio al enunciar satius est impunitum relinqui facinus nocentis quam innnocentem damnaril ${ }^{2}$, es decir, es preferible que se deje impune al culpable de un delito a que se castigue a un inocente; este escenario da un giro con la Inquisición, en la Edad Media ${ }^{13}$.

Como se menciona en el párrafo anterior, no se puede afirmar que en la práctica de la presunción de inocencia, haya sido utilizada a lo largo de la historia como criterio preponderante, pues solo basta voltear un poco la mirada hasta la época de la Inquisición y darse cuenta que dicha práctica, resultaba totalmente contraria a la presunción de inocencia, pues en los procesos inquisitivos claramente se presumía la culpabilidad del sujeto, pese a que formalmente la presunción de inocencia era reconocida.

Se puede afirmar que este principio alcanza su punto más álgido con la Ilustración, puesto que esta época supone un cambio radical

11 García FALCONí, R. op. cit., p. 74.

12 Maciá, C., y Galván, M. "Presunción de inocencia y deontología periodística: el 'caso Aitana'", Revista Latina de Comunicación Social. N. ${ }^{\circ} 67,2012$, p. 368.

13 Nieva, J. op. cit., pp. 4 y 7. 
en la práctica penal, que surge de la crítica al proceso inquisitivo, en el cual el imputado es tratado como culpable, de tal manera que éste se veía en la necesidad de probar su inocencia, si quería evitar la condena ${ }^{14}$. En la Ilustración, este principio toma fuerza gracias a toda la corriente garantista de respeto de la dignidad y a autores, como BECCARIA, quien rechaza esta figura, afirmando que supone la imposición de una pena a un sujeto, cuya culpabilidad aún no ha sido determinada.

Esta crítica, sostenida en la Ilustración, rápidamente fue recogida por la Declaración del Hombre y el Ciudadano ${ }^{15}$, de 1789, alcanzando de esta manera la presunción de inocencia su universalización y a la luz de esta Declaración universal, logra su reconocimiento en la mayoría de instrumentos internacionales, en las constituciones de los distintos países y sus ordenamientos jurídicos, hasta que en la actualidad, se la considera un principio fundamental para hacer efectivo el debido proceso en materia penal y garantizar los derechos más importantes de los ciudadanos.

$\mathrm{Al}$ referirse a los antecedentes de la presunción de inocencia no se puede dejar de mencionar a CARRARA ${ }^{16}$, uno de los más grandes exponentes de la Escuela Clásica del Derecho Penal, con quien la presunción de inocencia alcanza su máxima amplitud por su formulación de los postulados de los que parte este principio;

14 Vegas, J. Presunción de Inocencia y prueba en el proceso penal. Madrid, La Ley S.A., 1993, p. 15.

15 Artículo 9.- Puesto que todo hombre se presume inocente mientras no sea declarado culpable, si se juzga indispensable detenerlo, todo rigor que no sea necesario para apoderarse de su persona debe ser severamente reprimido por la ley.

Carrara, en Vegas, J. op. cit., p. 23. 
además, por su trascendental frase: Haced esto, porque el hombre de quien vosotros sospecháis es inocente y no podéis negarle su inocencia, mientras no hayáis demostrado su culpabilidad, y no podéis llegar a esa demostración, si no marcháis por el camino que os señalo.

\section{3.Ámbito del alcance de la presunción de inocencia en el proceso penal}

En el presente estudio acerca del principio constitucional de la presunción de inocencia, se observan varios elementos que la componen, los cuales implican requisitos indispensables para su pleno desarrollo, así como para los efectos que estos producen, por consiguiente, se han agrupado primordialmente en tres, desarrollados a continuación:

1) Ser tratado como inocente;

2) Actividad probatoria; $y$,

3) Certeza del juez.

\subsection{Ser tratado como inocente}

Mientras no exista una sentencia judicial en firme, está prohibido exhibir o hacer referencia de la persona como responsable o culpable de un determinado hecho delictivo; es una consecuencia de la constitucionalización de este derecho fundamental -goza de tutela judicial- como una parte del debido proceso, en tal virtud, es de aplicación directa, inmediata y vincula a todos los poderes del Estado -policías, fiscales, jueces y otros-; la presunción de 
inocencia impone un limite formal al ejercicio punitivo del Estado, que debe estar presente durante todo el proceso, por tal motivo, se debe tratar al procesado (o investigado) como inocente, mientras no se acredite lo contrario ${ }^{17}$.

Otro aspecto que se debe tener en cuenta, es la imposición de medidas cautelares, es decir, éstas no pueden actuar como una pena anticipada, restringiendo derechos del imputado; para que se imponga una medida cautelar, es necesario que éstas estén justificadas y sean razonables, en concordancia con las circunstancias que concurren en el proceso. Al respecto, se debe tener especial atención a la prisión preventiva, que es una medida que debe ser aplicada sólo de manera excepcional ${ }^{18}$.

Se concuerda completamente con el autor Tisnés PALANCiO ${ }^{19}$ en su afirmación de la necesidad de operar un cambio en la estructura mental, principalmente, de la sociedad, que en su mayoría, asimila automáticamente al investigado o procesado como culpable, situación que se marca aún más cuando va acompañada de una medida cautelar como la prisión preventiva, erradicar esta imagen del colectivo social se vuelve una tarea casi imposible; esta situación es distinta en casos excepcionales, por

17 Bustamante, M. “La relación del estándar de la prueba de la duda razonable y la presunción de inocencia desde el garantismo procesal en el Proceso Penal colombiano", Opinión Jurídica. vol. 9, N. ${ }^{\circ} 17$, 2010, p. 83 y ss.

18 CORDÓN, J. op. cit., pp. 93-94.

19 TISNÉS, J. afirma que las medidas de aseguramiento privativas de libertad quebranta la presunción de inocencia, además del derecho de libertad (p. 5). Tisnés, J. “Principio de Inocencia y medida de aseguramiento privativa de la libertad en Colombia. Un Estado constitucional de Derecho", Revista Ratio Juris. vol. VI, N. ${ }^{\circ} 13,2011$, p. 71. 
ejemplo, cuando la persona directamente implicada es familiar o de su círculo cercano.

En este ámbito de la presunción de inocencia, se ven también comprometidos los medios de comunicación social, debido a las actividades que realizan, inherentes a su función informativa, las cuales deben ser llevadas a cabo en el margen del respeto y cumplimiento de este derecho; esto implica principalmente no dar paso a la emisión de noticias, mediante las cuales se califique o estigmatice a una persona como partícipe o autor de un hecho delictivo hasta que no exista una sentencia, que así lo declare ${ }^{20}$; este precepto es de primordial importancia, en virtud del gran impacto que tienen los medios de comunicación en la sociedad y como orientadores del criterio, que se forma en la ciudadanía.

Este tipo de noticias tienen un efecto negativo para la persona, quien está siendo investigada o procesada, puesto que la sociedad da por cierto esas imputaciones y no la considera como sospechosa, sino que directamente asume la culpabilidad y peligrosidad de ese sujeto, esto es un rezago del sistema inquisitivo, en el cual se presumía la culpabilidad; esta situación empeora cuando esa noticia va acompañada de imágenes del sospechoso, siendo detenido o usando esposas, aunque después se ratifique la inocencia de esa persona, el criterio social respecto a ella no varía o lo hace mínimamente ${ }^{21}$.

20 CORdón, J. op. cit., p. 92.

21 Nieva Fenoll, J. "La razón de ser de la presunción de inocencia", InDret: Revista para el análisis del Derecho. N. ${ }^{\circ} 1,2016$, pp. 5 y ss. 


\subsubsection{Actividad Probatoria}

La presunción de inocencia está estrechamente vinculada con la actividad probatoria, en tal sentido, la actividad probatoria debe recaer, tanto sobre los elementos subjetivos y objetivos del tipo penal, como en la culpabilidad del sujeto, quien está siendo investigado. Además, esta actividad probatoria se la debe realizar, con respeto absoluto de los derechos fundamentales, garantizados constitucionalmente, y la respectiva normativa legal, esta actividad probatoria debe ser necesaria y suficiente para que la acusación sea considerada como una verdad probada; especialmente la prueba debe ser practicada, cumpliendo con los principios de igualdad, oralidad, contradicción, publicidad e inmediación ${ }^{22}$.

Como se señaló anteriormente, el derecho, objeto de análisis, implica una presunción iuris tatum, que exige, a fin de ser desvirtuada, un mínimo de actividad probatoria, respetando las garantías procesales. Lo que se busca es probar la existencia de un hecho punible y la culpabilidad del acusado, en consecuencia, la carga probatoria corresponde a la parte acusadora y no al acusado, éste no tiene que aportar ninguna prueba, puesto que él conserva su condición de inocente, asimismo, cuenta con la garantía de no declarar contra sí mismo, en tal virtud podría ser totalmente inactivo durante el período de prueba, sin que esta circunstancia implique que vaya a ser considerado culpable y condenado ${ }^{23}$.

\footnotetext{
22 Bustamante, M. op. cit., pp. 84-85.
}

23 JAÉn, M. Los principios de la prueba en el proceso penal. Santa Fe de Bogotá, Universidad Externado de Colombia, 2000, p. 38; en el mismo sentido, véase a Nieva, J. op. cit., p. 10. 
Se considera prueba de cargo válida aquella actividad que conduce razonablemente a dar por ciertos hechos que incriminan al acusado en un determinado delito, a fin de que con el cumplimiento de estos presupuestos, se cumpla la prueba:

1) Debe evidenciar un contenido objetivamente incriminatorio, dicho de una manera más sencilla, implica que de la prueba se pueda deducir directamente la responsabilidad del acusado en un determinado hecho; y,

2) Que exista la confianza suficiente que dichos resultados corresponden a la verdad ${ }^{24}$.

Ciertamente, desarrollar los temas relativos a la prueba sería muy extenso y sobrepasaría el objeto del presente estudio, no obstante, es importante hacer una breve referencia a aquellas prácticas probatorias, que se encuentran estrechamente relacionadas con la presunción de inocencia como, por ejemplo, la prueba de indicios; es aquélla que permite acreditar un determinado hecho -del que no se cuenta con prueba directa-, a partir de indicios que han sido probados; para que este tipo de prueba tenga validez, los hechos constitutivos de delitos deben deducirse de esos indicios, a través de un proceso mental razonable y acorde con las reglas de la experiencia y de la lógica ${ }^{25}$.

La prueba de referencia por sí sola no puede desvirtuar la presunción de inocencia, se busca que el referido sea directamente escuchado sobre los hechos, si éste no comparece, de poco servirá

24 VEGAS, J. op. cit., pp. 130-131.

25 JAÉn, M. Los principios de la prueba en el proceso penal. Santa Fe de Bogotá, Universidad Externado de Colombia, 2000, pp. 41-42. 
la referencia a é ${ }^{26}$. Es importante considerar que la declaración incriminatoria de un coimputado, por sí sola, no es suficiente para desvirtuar la presunción de inocencia ${ }^{27}$, tal como lo refiere la sentencia del TS, N. ${ }^{\circ} 45 / 2011$, de 11 de febrero:

En definitiva, la singularidad del testimonio del coimputado -cuando es única prueba- es que es insuficiente para fundar en él una condena, su declaración debe venir confirmada por datos externos, es decir de otra fuente de prueba distinta de la facilitada por el propio imputado.

\subsubsection{Certeza del juez}

El derecho a la presunción de inocencia puede ser lesionado de dos maneras: la primera, cuando se tenga por cierta la culpabilidad del acusado y ésta no haya sido probada, de conformidad con la Ley y la segunda, cuando exista duda sobre la culpabilidad del acusado y sea condenado ${ }^{28}$. Se trata de un derecho que impide que la sentencia declare la certeza de hechos y/o participación del investigado en una conducta penal, cuando estos no pudieron reputarse probados conforme la Ley prescribe.

La certeza es la íntima convicción, es la seguridad y firmeza en el conocimiento, y este elemento extremadamente necesario no puede ser equivocado en la sentencia condenatoria, aunque hay que recordar que el juez resuelve, según su leal saber y entender, atendiendo a los principios de la sana crítica, las reglas

\footnotetext{
26 Ibíd. p. 56.

27 Ibíd. p. 51.

28 VeGAS, J. op. cit., pp. 42-43.
} 
de la experiencia, con base en la prueba pertinente, debidamente actuada, y respetando todas las garantías. Sin embargo, la sentencia condenatoria sólo procede, cuando el Juez o Jueces se convencen de la efectividad de los cargos, contenidos en la acusación, a través de la prueba lícita y legalmente producida en juicio ${ }^{29}$.

Si no existe prueba alguna que determine la culpabilidad del acusado, no es posible imponer una condena, aunque el juez esté íntimamente convencido de la responsabilidad de éste, puesto que en concordancia con la presunción de inocencia, no se admite un conocimiento intuitivo, por parte del juzgador, sino que éste debe ser racional y fundamentado en la prueba, practicada dentro del proceso de conformidad con la Ley ${ }^{30}$. Por lo antes expuesto, la motivación de la sentencia es indispensable y actúa como garantía de la presunción de inocencia ${ }^{31}$.

La incertidumbre ha sido un problema latente desde el Derecho romano, asimismo, las respuestas que se han dado a lo largo del tiempo también han sido muy diversas; no obstante, a partir de la Revolución Francesa, se establece la absolución libre y definitiva del acusado, si no existe certeza -más allá de toda duda razonable- sobre los hechos, o sobre la responsabilidad del acusado en el momento de dictar sentencia; en la actualidad, sigue vigente la disposición establecida en 1789, eso quiere decir que en caso de duda o incertidumbre fáctica, se debe resolver, atendiendo al

\footnotetext{
29 García, J. Presunción de inocencia y certeza, Derecho Ecuador. 2010, párr. 15 y ss. (versión digital)

30 VegAs, J. op.cit., pp. 47-48.

31 CoRdón, J. op, cit., 2012, p. 101.
} 
principio constitucional in dubio pro reo -ante la duda, a favor del reo- y se debe ratificar la inocencia ${ }^{32}$.

En este punto, se ha producido una colisión en la dogmática penal, puesto que, por una parte, están aquellos que afirman que: el principio de in dubio pro reo es la expresión del derecho continental de la presunción de inocencia $[. . .]^{33}$, mientras que la otra parte, se decanta por la tesis de que ambos principios son diferentes. Por un lado, el in dubio pro reo hace referencia a la estricta valoración de la prueba (criterio subjetivo), mientras que la presunción de inocencia está presente en todo el proceso y en lo que respecta a la prueba, comprende la necesidad de una carga probatoria, bajo las garantías establecidas (criterio objetivo) ${ }^{34}$.

\section{Los medios de comunicación y los juicios paralelos}

\subsection{Los medios de comunicación}

Los medios de comunicación son los instrumentos, mediante los cuales se informa a la sociedad sobre los acontecimientos recientes más trascendentes, tanto a nivel local, nacional e internacional; son los mismos medios de comunicación quienes otorgan mayor o menor importancia a un determinado suceso, es decir, tienen el poder de ubicar en la cima del debate público un hecho determinado, consiguiendo de esta manera centrar la atención de la colectividad en ese suceso; [...] Los medios

\footnotetext{
32 VeGAS, J. op. cit., pp. 202-203.

33 Bustamante, M. op. cit., p. 85.

34 El autor hace un análisis amplio sobre las diferencias entre la presunción de inocencia y el in dubio pro reo, así como de sus implicaciones y peligros de tratarlas como iguales. ORTEGO, F. op. cit., p. 25.
} 
de comunicación de masas, en consecuencia, actúan como auténticos agentes de control social, que reconocen y delimitan cuáles son los problemas sociales al tiempo que generalizan enfoques, perspectivas y actitudes ante ellos ${ }^{35}$.

El papel que juegan los mass media -medios de comunicación de masas- dentro de la sociedad es muy importante y en lo que ocupa a este estudio, respecto al Derecho penal, ejercen una marcada influencia, se han convertido en actores fundamentales de la política criminal ${ }^{36}$. Por ello, es que se ha llegado a considerar a los medios de comunicación como el cuarto poder de un Estado, añadiendo este último a la famosa división de poderes de Montesquieu. La correcta labor de los medios de comunicación debe ser eficiente, comprometida, veraz, imparcial y objetiva, porque sólo así se puede ayudar a construir una sociedad más crítica y participativa, que aporte positivamente en las decisiones estatales.

Esta influencia en la sociedad, por parte de los medios de comunicación, se ha logrado a través de dos herramientas: la agenda setting -los temas de los que se va hablar- y la técnica del framing -el contexto en el que se va a hablar-; el primero de ellos, la tematización de la agenda es aquel proceso, mediante el cual se selecciona y se determinan los hechos que van a ser noticia, todo esto, apoyándose en intereses particulares de los medios de comunicación, de quienes lo integran o de los grupos de poder a los que responden ${ }^{37}$.

\footnotetext{
35 SAnz, N. "Política criminal: actualizada a las reformas del 2015", Ratio Legis. Salamanca, 2016, pp. 110-111.

36 Ibíd.p. 111.

37 Ibíd.
} 
Los medios de comunicación crean el marco de la realidad, los denominados frames, que son solamente puntos de vista, que determinan el enfoque y la visión de los hechos, buscando resaltar algunos aspectos específicos y desestimando otros; estos elementos son transmitidos y compartidos a la sociedad ${ }^{38}$, en tal virtud, son los medios de comunicación los que, a la postre, determinan cuáles son los hechos admisibles y cuáles no, los que merecen reproche y los que no, así como lo que es legítimo y lo que no lo es ${ }^{39}$; en consecuencia, los medios de comunicación social son los que, finalmente, determinan la reacción de la sociedad y la posición que se debe tomar frente a un hecho determinado.

Los medios de comunicación son los generadores de la opinión pública, que no es más que es un poder invisible, que es capaz de ejercer presión sobre la sociedad y sobre quienes la gobiernan, es de carácter variable, puesto que puede cambiar de una semana a otra; la opinión pública se crea a través de lo que las personas hablan, ven, oyen o asimilan, sobretodo, de los medios de comunicación, tiene el poder de enraizarse, tanto que puede convertir en verdad, algo que no existe ${ }^{40}$.

Como se mencionó en párrafos anteriores, los medios de comunicación responden a sus propios intereses y esto depende específicamente del rating -índices de audiencia-, puesto que como todo negocio, necesita generar un lucro, es por ello que

38 SÁNChez, M., y OrdóÑEz, A. Juicios mediáticos y presunción de inocencia. Málaga, Revista La Ley, N. ${ }^{\circ}$ 57, 2016, pp. 41-43.

39 Ibíd. p. 51.

40 Valencia, C. "Juicios paralelos en Colombia y la imposibilidad de aplicar el principio de presunción de inocencia", Analecta Política. vol. VI, N. 11, 2016, p. 255 y ss. 
los mass media cada vez tienen que buscar ser más agresivos que la competencia y ganar terreno, más aun en un mundo tan globalizado como el actual, en el cual las tecnologías ya son parte de la vida de todas las personas; adicionalmente a esto, los medios de comunicación responden a ciertas tendencias políticas, se van ubicando en distintos sectores, dentro de un Estado, y sus acciones están encaminadas a responder a sus propios posturas.

El principio de publicidad procesal es parte del debido proceso, contiene el derecho de ser juzgado, mediante un juicio público, nace como una garantía individual, que protege al ciudadano de un exceso o abuso del poder estatal, pero en su aplicación beneficia a todas las personas porque permite evidenciar el manejo de la administración de la justicia; esto se logra no solo con las personas, que acuden a una audiencia, sino que se generaliza para toda la sociedad, debido a las acciones de los medios de comunicación, los cuales transmiten e informan estos sucesos ${ }^{41}$.

La garantía que ofrece el principio de publicidad, deja paso así a un equívoco principio de publicación, en el que todo se difunde, desde el momento mismo del inicio de las investigaciones, sin que el acusado pueda defender su inocencia ${ }^{42}$.

41 LetURIA, F. “La publicidad procesal y el derecho a la información frente a asuntos judiciales. Análisis general realizado desde la doctrina y jurisprudencia española", Revista Chilena de Derecho. vol. XLV, N. ${ }^{\circ}$, 2018, p. 649 y ss. En el mismo sentido, véase a ARISTIZÁBAL, K., et al. "Alcance del derecho a la información de los medios de comunicación masivos frente al debido proceso de los implicados penalmente", Jurídicas CUC. N. 10 (1), 2014, p. 204 y ss.

42 SÁnchez, M., y Ordóñez, A. op, cit., p. 126. 
La garantía del respeto a la libertad de información es propio de los gobiernos democráticos, a diferencia de los regímenes absolutos, que se caracterizan por la censura. Es un derecho reconocido constitucionalmente, como la mayoría de derechos, no tiene carácter absoluto, trae intrínsecas obligaciones que cumplir y su ejercicio no puede perjudicar el cumplimiento de los demás derechos ${ }^{43}$. Es un derecho de doble vía, es decir, no solo se trata de la divulgación de información -noticias, opiniones, entre otras-, sino que también comprende obtener la información verídica e imparcial, implica tanto a quien informa, como a quien recibe esa información ${ }^{44}$.

La urgencia de información en determinados procesos, o el interés por mostrar avances puede dar lugar a que se den como pruebas contrastadas lo que en verdad son valoraciones interesadas para alguna de las partes; al igual que puede dar lugar a que no exista un verdadero filtro probatorio, o que dicha información no sea contrastada $^{45}$. De igual manera, se establece que los juicios paralelos, en su máxima expresión, tienden a buscar testigos, pruebas, peritos, declaraciones, todo aquello que ayude a dar solidez a sus afirmaciones, o de la tesis que manejan y que, por otro lado, desestimen la hipótesis contraria ${ }^{46}$.

Es importante mencionar que frente a la noticia, no hay controles previos, aunque de ella se pueden derivar responsabilidades

43 SuÁREZ, G. "La responsabilidad periodística, límite legítimo al ejercicio profesional”, Palabra Clave. vol. IX, N. ${ }^{\circ} 1,2006$, p. 87.

44 AristizÁbAL, K. et al. op. cit., p. 206 y ss.

45 Ibíd. p. 115.

46 Montalvo, J. “Los juicios paralelos en el proceso penal: ¿anomalía democrática o mal necesario?", Universitas. Revista de Filosofía, Derecho y Política. vol. XVI, 2012, p. 114. 
posteriores a su emisión, la principal herramienta utilizada en estos casos es la rectificación ${ }^{47}$. Es mediante este instrumento, el cual se corrige una noticia falsa, o que carece de objetividad, que está causando un perjuicio a una persona; es el medio de comunicación el cual se debe encargar de rectificar la noticia, con una nueva publicación en igualdad de condiciones (proporcional a la anterior) y, además, debe asumir su equivocación, si el medio no rectifica la noticia, el afectado puede hacer uso de la vía judicial ${ }^{48}$.

Es importante contar con una herramienta, que permita rectificar los errores en los cuales caen los medios de comunicación, sin embargo, las rectificaciones, la mayoría de las veces, no surten el mismo efecto que la noticia original, es decir, aquella persona que para el colectivo social fue etiquetada como delincuente, es muy difícil que pierda ese estatus, de hecho, muchas veces ni la propia sentencia judicial, que ratifica la inocencia de una persona, llega a ser un presupuesto suficiente para revertir la estigmatización de la que fue víctima por los medios de comunicación y, por ende, de la sociedad. Es por ello que la necesidad de una ética profesional en esta rama es de trascendental importancia, es momento que los medios de comunicación tomen conciencia y desempeñen sus actividades con total responsabilidad.

\footnotetext{
47 Art. 66, num. 7.- El derecho de toda persona agraviada por informaciones sin pruebas o inexactas, emitidas por medios de comunicación social, a la correspondiente rectificación, réplica o respuesta, en forma inmediata, obligatoria y gratuita, en el mismo espacio u horario. Constitución Política DEL ECUADOR. 2008.
}

48 AristizÁbal, K., et. al. op. cit. p. 210 y ss. 


\section{2. Juicios Paralelos}

Son aquellos juicios que se dan de forma análoga en la sociedad, en la cual los medios de comunicación social fungen de jueces, se amparan en el derecho a la libertad de información ${ }^{49}$ y en el derecho a la publicidad ${ }^{50}$ de los procesos judiciales, salvo las excepciones determinadas en la Ley ${ }^{51}$, para de esta manera publicar y transmitir información, sobre algún caso específico, que por los hechos acontecidos, o por la calidad de una de las partes refleja un interés social. Los juicios paralelos son una suerte de engendros creados al calor de la desmesura de dos derechos fundamentales $[. . .]^{52}$.

49 Art. 18.- Todas las personas, en forma individual o colectiva, tienen derecho a: 1. Buscar, recibir, intercambiar, producir y difundir información veraz, verificada, oportuna, contextualizada, plural, sin censura previa acerca de los hechos, acontecimientos y procesos de interés general, y con responsabilidad ulterior.

2. Acceder libremente a la información generada en entidades públicas, o en las privadas que manejen fondos del Estado o realicen funciones públicas. No existirá reserva de información excepto en los casos expresamente establecidos en la ley. En caso de violación a los derechos humanos, ninguna entidad pública negará la información. Constitución POlíticA DEL ECUADOR. 2008.

50 Art. 76, núm. 7, literal d).- Los procedimientos serán públicos salvo las excepciones previstas por la ley. Las partes podrán acceder a todos los documentos y actuaciones del procedimiento. Constitución POLÍTICA DEL ECUADOR. 2008.

51 Art. 562.- Publicidad de las audiencias.- Las audiencias son públicas en todas las etapas procesales.

Son reservadas las audiencias sobre delitos contra la integridad sexual y reproductiva, violencia contra la mujer o miembros del núcleo familiar y contra la estructura del Estado constitucional. CódIGO ORGÁNICO InTEgral PENAL. 2014.

52 CORTÉs, E. "Juicios paralelos y derechos fundamentales del justiciable", Anuario de la Facultad de Derecho. vol. XXI, 2003, p. 138. 
Los juicios paralelos pueden darse en todas las ramas del Derecho, la realidad nos muestra que han centrado su atención principalmente en los procesos penales, se han concentrado en el fenómeno criminal y esto puede ser un aspecto positivo con la intención de evidenciar un problema social para, de esta manera, encontrar soluciones para combatirlo y, por otro lado, se encuentra el aspecto negativo, que es aquel que busca un protagonismo mediático, que garantice la sintonía y con ese objetivo, se vale de información inexacta, adulterada, mostrando cifras manipuladas y con claros sesgos en su emisión ${ }^{53}$; asimismo, al centrar la atención de la audiencia en un problema inexistente o no tan grave, dejan de lado aquellos temas importantes de los que no se quiere hablar.

Al ser los juicios penales los más afectados por los juicios paralelos, de igual manera sucede, con las garantías inherentes a ellos -el debido proceso y las garantías, que lo componen, se ven vulneradas en mayor o menor medida-; se debe recordar que el debido proceso se interpreta como un derecho absoluto ${ }^{54} \mathrm{y}$ es el encargado de accionar la función jurisdiccional del Estado y de proteger la dignidad humana, es por ello y por la trascendencia de este proceso, que en este evidente choque de intereses entre dos derechos constitucionales -información y debido proceso-, se debe procurar la máxima realización de este último.

Una correcta actuación de los medios de comunicación es aquella que busca, en la medida de lo posible, reducir las consecuencias dañinas para el investigado o procesado y su familia, lo cual

\footnotetext{
53 Fuentes, J. “Los medios de comunicación y el Derecho penal”, Revista Electrónica de Ciencia Penal y Criminología. N. ${ }^{\circ}$ 07-16, 2005, p. 16:3.

54 Aristizábal, K. op. cit., p. 2019.
} 
implica dar la menor cantidad de detalles o datos personales, omitir su nombre, o evitar su clara identificación, usar una terminología adecuada, sobretodo cuando se va a hacer referencia al procesado, no hacer uso de insultos o calificativos, recalcar que se trata de presuntos y supuestos no confirmados, evitar el uso de fotografías o imágenes del procesado, transmitir los hechos sin una toma de postura personal ${ }^{55}$.

El problema surge cuando estos juicios se formulan sobre datos o indicios erróneos, o con posiciones sesgadas a favor o en contra de determinadas personas, que desembocan en linchamientos mediáticos ${ }^{56}$. Los medios de comunicación se identifican con instituciones legitimadas socialmente, o con la parte que, a su juicio, es más vulnerable para mediar una realidad compleja y presentar esta única versión de los hechos como cierta e indiscutible ${ }^{57}$.

En la narración de los hechos, que se dan por ciertos, se destacan determinados aspectos (condiciones de vida, nacionalidad, raza, color de piel, entre otros), tanto de la víctima como de la persona, quien ha sido señalada como culpable, se tiende a emplear términos peyorativos para el acusado, emitiendo, desde ese momento, una sentencia en su contra. A partir de ese instante, se produce la estigmatización de una persona, que muchas veces es inocente y debido a estos juicios paralelos, queda marcada o condicionada, de por vida; estas personas han sufrido una condena inmediata dictada por la opinión pública ${ }^{58}$.

\footnotetext{
55 Maciá, C., y Galván, M. op. cit., pp. 370-371.

56 SÁnchez, M., y Ordóñez, A. op. cit., pp. 24-25.

57 Ibíd. p. 43.

58 FuENTES, J. op. cit., p. 16, 17 y ss.
} 
Es importante recordar que las noticias se manejan sobre hipótesis de los medios de comunicación, hipótesis que pueden ir variando constantemente, en muchos casos, dependiendo del rating que estos provocan y a partir de las cuales se le asigna un papel a cada una de las partes o a cada una de las personas investigadas; estos juicios son difundidos por los medios de comunicación social, calificando generalmente de culpables a las personas investigadas, lo cual aumenta o se afianza cuando de por medio existen medidas cautelares, especialmente prisión preventiva o se hace pública su captura, la peligrosidad del sujeto es ponderada ${ }^{59}$.

En cuanto a las fuentes, se evidencia que el acceso a expedientes en mayor medida viene de la parte acusadora, sea pública o privada, lo que trae como consecuencia que generalmente la versión de los medios de comunicación sea incriminatoria -en contra del acusado-, versión que es aceptada y asimilada por la sociedad, que inmediatamente empieza a emitir juicios de valor en contra la persona acusada y también se genera una expectativa condenatoria, en cuanto a la resolución de ese proceso ${ }^{60}$.

La incursión de los medios de comunicación en determinados casos que por su contenido se vuelven de interés social, implica también que la información, o la noticia lleguen a quien imparte justicia, generando presión sobre quien toma la decisión ${ }^{61}$, más

\footnotetext{
59 Valencia, C. op. cit., p. 268 y ss.

60 SÁncheZ, M., y OrdóÑEz, A. op. cit., p. 95 y 102.

61 BARRERO, A. señala que un trabajo investigativo afirma que el $82.35 \%$ de los jueces dictaron medidas cautelares motivados por la presión social. BARRERO, A. "Juicios paralelos y Constitución: su relación con el periodismo", Ámbitos. N. ㅇ 6, 2001, p. 183; BARRIOS, Á. et al. "El principio de presunción de inocencia en la aplicación de la prisión preventiva", Dominio de las ciencias. vol. III, N. ${ }^{\circ}$ 2, 2017, p. 644.
} 
aun cuando es la propia sociedad, influenciada por la publicidad, la que reclama sentencia y se encuentran expectantes por una resolución; en tal virtud, no se puede negar que implica una contaminación del proceso, ocasionando de esta manera que la imparcialidad e independencia de los jueces, se pueda ver afectada; por ello, se dificulta el trabajo de los administradores de justicia para distinguir una noticia de lo que es una prueba.

Otra de las consecuencias de los juicios paralelos y quizá la más importante, es que este tipo de juicio carece de segunda instancia: quien es considerado culpable difícilmente puede ser rehabilitado socialmente. No hay quien enmiende una primera plana con un veredicto de la prensa, ni siquiera la verdad emitida por los tribunales de justicia, que desvirtúen tal imputación de culpabilidad $^{62}$. Implica un problema aún más grave cuando ese juicio paralelo ha incidido de forma tal, que el investigado ha sido declarado culpable, sin que realmente haya cometido ese hecho; la justicia es falible, pero su misión es buscar la verdad y no poner en riesgo los derechos humanos y procesales alcanzados a lo largo de estos años.

La justicia no es solo eficacia, va más allá. Implica el respeto de garantías mínimas propias de un Estado social y democrático de Derecho, que es fruto de siglos de lucha social y política fenómenos que han conllevado a sociedades en las que la protección de la dignidad de la persona humana ha de ser medio y fin de toda actuación estatal ${ }^{63}$.

\footnotetext{
62 SÁNCHEZ, M., y OrdóñEZ, A. op. cit., pp. 31-32.

63 Yon, R., y SÁNCHEZ, A. op. cit., p. 135.
} 
Con el fin de poder aterrizar a la realidad los conceptos esbozados a los largo de este trabajo, se pretende tomar un caso y mediante un análisis de los hechos que se realizaron, tanto en el colectivo social, como aquéllos que se desprenden de la actividad judicial procesal poder determinar la función que están jugando los medios de comunicación ecuatorianos.

\section{Caso Karina del Pozo}

El 19 de febrero de 2013 desaparece Karina del Pozo, una joven quiteña, de 20 años de edad, quien fue vista por última vez en la casa de uno de sus amigos, en la cual se desarrollaba una reunión social y en donde la joven se relacionó y compartió momentos con algunos de sus amigos y conocidos. El 20 de febrero, en horas de la madrugada, Karina del Pozo fue asesinada. Las redes sociales fueron el primer medio usado para reportar la desaparición de la joven mencionada, varias publicaciones con su foto, acompañadas con mensajes de Ayúdanos a encontrarla y Desaparecida se volvieron virales, los medios de comunicación, por ejemplo, Teleamazonas, hicieron eco de estas publicaciones en su cuenta de Twitter el 22 de febrero.

Siete días más tarde, el 27 de febrero, su cuerpo fue hallado en alto grado de descomposición cerca de la quebrada de Llano Chico, en el sector nororiente de la capital ecuatoriana. Los medios de comunicación daban la noticia del reciente hallazgo, Ecuavisa T.V., 27 de febrero de 2013: Encuentran el cuerpo de la modelo desaparecida, Karina del Pozo. Días posteriores al hallazgo del cuerpo de la joven, fueron detenidas para investigaciones cinco personas, las cuales fueron las ultimas en ver con vida a Karina del Pozo y con quienes, según versiones recogidas, la joven salió la noche del 19 de la casa donde se encontraba. Allanan casas de 
tres detenidos por el asesinato de Karina del Pozo fue la noticia del Diario El Universo, en la cual se pueden hallar datos como la ubicación de los domicilios de los detenidos.

Al poco tiempo de lo sucedido, ya circulaban en las redes sociales los nombres e imágenes de los cinco detenidos e incluso de alguno de ellos, se hacía especial referencia y se lo etiquetaba de violador y asesino, en razón de las actividades que practicaba. Los medios de comunicación sensacionalistas no se quedaron atrás, así titulaba la noticia un periódico de circulación nacional: Uno de los detenidos tiene fama de morboso.

Cada nueva diligencia era noticia, así como la reconstrucción de los hechos, la confesiones de los detenidos, entre otras; los primeros datos sobre la muerte establecen que Karina del Pozo fue agredida sexualmente, estrangulada y golpeada brutalmente, con un objeto contundente en su cabeza, datos que, posteriormente, se logran validar cuando el informe del perito forense establece como causa de la muerte un traumatismo cráneo encefálico muy grave.

Se revela cómo asesinaron a Karina del Pozo titula la noticia del canal de T.V. Teleamazonas, un reportaje de 1 hora 22 minutos, de fecha 6 de marzo de 2013, en la diligencia de ampliación de la toma de versiones, en la cual, por un lado, se ven imágenes de los familiares de uno de los detenidos, quienes tratan de evitar que los medios de comunicación los graben; además, cuenta con el testimonio de un abogado, quien describe como atroz el crimen contra Karina del Pozo, haciendo la aseveración: El señor David Piña es el que le agrede con una roca y le destroza el cráneo.

Este hecho conmovió a la sociedad ecuatoriana, provocando algunas marchas en rechazo a estos actos violentos y en contra de 
la violencia contra las mujeres, al igual que un clamor general, que pedía justicia para Karina del Pozo; fue tal el impacto causado por este delito, que es a raíz de este caso que se empieza a hablar de la tipificación del femicidio, tipo penal que un año más tarde, será incluido en el ordenamiento jurídico.

A mediados de año, dos de los cinco detenidos fueron puestos en libertad, por con un dictamen de abstención, y ya para septiembre de 2013, los otros tres acusados fueron condenados, en calidad de autor y coautores, a 25 años de reclusión mayor, la pena máxima establecida para ese delito, sin embargo, ya desde febrero, ellos fueron condenados como asesinos y violadores por la sociedad.

Cuatro años más tarde, se reabre socialmente el caso Karina del Pozo ante nuevos supuestos otra vez publicitados por los medios de comunicación, ¿Quién mató a Karina del Pozo? Es el titular del canal de T.V. Teleamazonas, el cual dedica un reportaje de alrededor de 15 minutos: de éste se infiere que uno de los tres condenados por la muerte de la joven, sería inocente, se fundamentan en que no hubo prueba suficiente para condenarlo, puesto que su culpabilidad solo fue sostenida por el testimonio de uno de los coimputados, pero que nunca se encontraron otras pruebas materiales, que lo incriminen, como sí se dio en el caso de los otros dos condenados.

Existe un corto documental ${ }^{64}$ sobre uno de los sentenciados, en el cual participa una periodista del canal de T.V. Teleamazonas; la periodista reconoce que tras la mediatización de este caso, la declaración del fiscal, que fue reproducida en los medios de

64 Este documental está disponible en la siguiente página web: https://www.youtube.com/watch?v=v9J 0kxMfmP4. 
comunicación, [...] hizo pensar a todos que el asesino era el chico David Piña [...]; luego de investigar el proceso, descubre un montón de inconsistencias y en palabras de la misma periodista, se afirma: aquí no se determinó culpabilidad de nadie; y, concluye que: [...] te das cuenta que no hay una sola prueba, que vincule al chico David Piña con el lugar de los hechos con el asesinato [...].

Ante esta situación, cabe preguntarse: ¿fue la presión ejercida, por los medios de comunicación y la sociedad, la que llevó, a los administradores de justicia, a pasar por alto las garantías básicas del proceso penal y los principios fundamentales como la presunción de inocencia y el in dubio pro reo? 


\section{CONCLUSIONES}

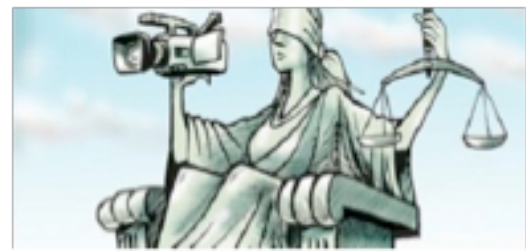

65

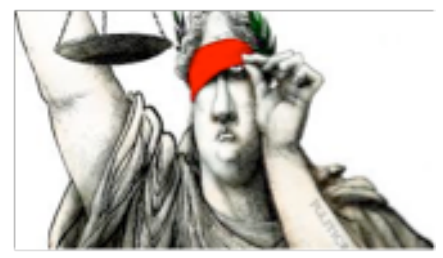

66

Los hechos son sagrados; las opiniones libres Charles P. Scott (1921)

La presunción de inocencia hace referencia básicamente al proceder de las autoridades, con relación a la consideración y respeto a la condición de inocente del sujeto, quien ha sido imputado de un determinado delito; de igual forma, comprende las respuestas, que puedan provenir de los comportamientos sociales y, especialmente, las actuaciones llevadas a cabo por los medios de comunicación, en virtud del gran impacto que producen las noticias en la opinión pública y en la ciudadanía.

65 Imagen disponible en la siguiente página web: https://www.google. $\mathrm{com} /$ url?sa=i\&source=images\&cd=\&ved=2ahUKEwjX756zpt3mAhW kzVkKHZUHCwQQjx6 BAgBEAQ\&url=https\%3A\%2F\%2Fgradocero prensa.wordpress.com $\%$ 2F2017\%2F06\%2F03\%2Fjusticia-mediatica-losjuicios-paralelos-2\%2F\& psig=AOvVaw2kilH_T_uPttfcJBnLTxkn\&ust= 1577792807657050

Imagen disponible en la siguiente página web: https://www. google.com/url?sa=i\&source=images\&cd=\&ved=2ahUKEwjYpqj Np93mAhUlvlkKHZdCCwQjRx6BAgBEAQ\&url=https\%3A\%2F\% 2Fabcblogs.abc.es\%2Ffederico -ysart\%2Fpolitica\%2Fjusticia-ciegaquia.html\&psig=AOvVaw1fNr_xJYrhgPO2KvJWZT5\&ust=157779 3131321308. 
En el presente tema de investigación, efectivamente, se evidencia una contraposición entre derechos; por un lado, el derecho a la libertad de información y a la publicidad y, por el otro, el derecho a la intimidad, a la presunción de inocencia y a un juicio justo. En primer lugar, se reconoce y garantiza el derecho a la libertad de información, que tienen los medios de comunicación, sin embargo, este derecho debe ser ejercido de manera responsable, el acceso a la información, por parte de los medios de comunicación, debe ser directo y fidedigno, asegurando de esta manera que la información que se publique, sea verdadera y neutral.

Se considera que los medios de comunicación deben incidir en los procedimientos penales, pero no como un acusador más, sino como aseguradores de las garantías procesales, ante posibles abusos o errores, que puedan darse por parte del Estado, a través del poder punitivo, el cual debe velar por el efectivo cumplimiento del debido proceso.

Tal y como se realizan los juicios paralelos en la actualidad se puede afirmar que la justicia paralela NO es justicia, sólo se puede llamar justicia a aquélla que ha sido llevada a cabo por los administradores de justicia, en la que priman la imparcialidad e independencia, que ha sido desarrollada bajo estricta observancia de las garantías procesales, aquélla en la que no medie interés alguno más allá de buscar la verdad de los hechos.

No se puede permitir que sean los medios de comunicación social los que emitan la sentencia en contra de una persona, si bien existe la libertad de expresión e información, bajo ningún motivo se puede justificar la vulneración de la presunción de inocencia de las personas investigadas, las consecuencias que conllevan esta incriminación de los medios de comunicación 
terminan, incidiendo en el proceso judicial, ponen al acusado en la posición de probar su inocencia, rompiendo así esta garantía fundamental de la presunción de inocencia, la cual es inherente a todas las personas.

En una época tan digitalizada e inundada por la tecnología y presas de las redes sociales, como la que vivimos, se hace indispensable generar conciencia en toda la colectividad sobre:

1. La importancia de respetar los derechos de las personas, más aun cuando son tan fundamentales como los del debido proceso;

2. No usar las nuevas tecnologías como instrumentos de linchamientos y acusatorios; $\mathrm{y}$,

3. No asumir como verdades absolutas las noticias de los medios de comunicación, puesto que también es nuestro deber, investigar y contrastar antes de emitir un criterio.

Se cree firmemente que la justicia debe seguir siendo ciega y debe empuñar en su mano la espada de dos filos, la cual simboliza el poder, la razón y la justicia y no una cámara de video, que implique la mediatización y parcialización de la verdad jurídica. 


\section{BIBLIOGRAFÍA}

ARISTIZÁBAL, K., et al. “Alcance del derecho a la información de los medios de comunicación masivos frente al debido proceso de los implicados penalmente", Jurídicas CUC. N. ${ }^{\circ} 10$ (1), 2014. (electrónico)

BARRERO, A. "Juicios paralelos y Constitución; su relación con el periodismo", Ámbitos. N. ${ }^{\circ}$ 6, 2001. (electrónico)

BARRIOS, Á., et al. "El principio de presunción de inocencia en la aplicación de la prisión preventiva", Dominio de las ciencias. vol. III, N. ${ }^{\circ}$ 2, 2017. (electrónico)

BECCARIA, C. De los Delitos y de las Penas. Santa Fé de Bogotá, Editorial Temis S.A., 2006.

BOUZA, F. "La influencia de los medios en la formación de la opinión pública: los procesos jurídicos y los juicios paralelos", Doxa comunicación: revista interdisciplinar de estudios de comunicación y ciencias sociales. $\mathrm{N} .^{\circ} 5$, 2007. (electrónico)

BUSTAMANTE, M. "La relación del estándar de la prueba de la duda razonable y la presunción de inocencia desde el garantismo procesal en el Proceso penal colombiano", Opinión Jurídica. vol. IX, N. ${ }^{\circ} 17,2010$. (electrónico) 
CABANEllas, G. Diccionario Jurídico Elemental. 18. a edición. Santa Fé de Bogotá, Heliasta, 2006.

COLÁs, A. "La influencia de los medios de comunicación en la administración de justicia a propósito de un caso mediático. Comentario a la sentencia del juzgado de menores de Sevilla, N. ${ }^{\circ}$ 1. Sentencia de 24 marzo de 2011 (ARP 2011, 2870)", Revista Boliviana de Derecho. N. 19, 2015. (electrónico)

CORDÓN, J. Prueba indiciaria y presunción de inocencia en el proceso penal. Madrid, Instituto Vasco de Derecho Procesal, 2012.

CORTÉS, E. "Juicios paralelos y derechos fundamentales del justiciable”, Anuario de la Facultad de Derecho. Tomo XXI, 2003. (electrónico)

ESCOBAR, E. "El derecho a la información y los medios de comunicación”, Opinión Jurídica. vol. I, N. ${ }^{\circ}$ 1, 2002. (electrónico)

FUENTES, J. "Los medios de comunicación y el Derecho penal", Revista Electrónica de Ciencia Penal y Criminología. N. ${ }^{\circ}$ 7-16, 2005. (electrónico)

García, J. "Presunción de inocencia y certeza". Derecho Ecuador. 2010. Disponible en la siguiente página web: http://www.derechoecuador.com/articulos/detalle/ archive/doctrinas/procedimientopenal/2010/06/17/ presuncion-de-inocencia-y-la-certeza. (electrónico) 
. "El principio procesal de inocencia en el COIP", Derecho Ecuador. 2014. Disponible en la siguiente página web: http://www.derechoecuador.com/articulos/detalle/ archive/doc trinas/derechopenal/2014/03/27/el-principioprocesal-de-inocencia-en-el-coip. (electrónico)

GARCÍA FALCONÍ, R. Código Orgánico Integral Penal Comentado. Quito, Latitud Cero, 2014.

HARbotTle, F. "Independencia judicial y juicios penales paralelos", ACADEMO. Revista de investigación en Ciencias Sociales y Humanidades. vol. IV, N. ${ }^{\circ}$ I, 2017. (electrónico)

JAÉN, M. Los principios de la prueba en el proceso penal. Bogotá, Universidad Externado de Colombia, 2000.

. Derechos fundamentales del proceso penal. Bogotá, Editorial Ibáñez, 2006.

LETURIA, F. "La problemática de los juicios paralelos en la jurisprudencia y doctrina española", Revista Ius et Praxis. Año 23, N. ${ }^{\circ} 2,2017$. (electrónico)

. "La publicidad procesal y el derecho a la información frente a asuntos judiciales.Análisis general realizado desde la doctrina y jurisprudencia española". Revista Chilena de Derecho. vol. XLV, N. ${ }^{\circ}$ 3, 2018. (electrónico)

MACIÁ, C., y GALVÁN, M. «Presunción de inocencia y deontología periodística: el "caso Aitana”», Revista Latina de Comunicación Social. N. ${ }^{\circ}$ 67, 2012. (electrónico) 
Montalvo, J. "Los juicios paralelos en el proceso penal: ¿anomalía democrática o mal necesario?”, Universitas. Revista de Filosofía, Derecho y Política. vol. XVI, 2012. (electrónico)

MUÑOZ, G. "Debido proceso, presunción de inocencia, derecho a la defensa, In Dubio Pro Reo y principio de legalidad frente a la libertad de información", Derecho penal y criminología. vol. XXII, N.॰71, 2001. (electrónico)

NIEVA, J. "La razón de ser de la presunción de inocencia", InDret: Revista para el análisis del Derecho. N. ${ }^{\circ}$ 1, 2016. (electrónico)

ORTEGO, F. "La delimitación entre el principio in dubio pro reo y la presunción de inocencia en el proceso penal español". Revista Chilena de Derecho y Ciencia Política. vol. IV, N. 3, 2013. (electrónico)

PARRA, J. "Presunción de inocencia, in dubio pro reo y principio de integración", Derecho penal y Criminología. vol. 21, N. ${ }^{\circ} 68,2000$. (electrónico)

PICÓ I JUNOY, J. Las garantías constitucionales del proceso. Barcelona, Bosch, 2012.

RUSCONI, M. "Principio de inocencia e in dubio pro reo", Jueces para la democracia. $\mathrm{N} .{ }^{\circ} 33,1998$. (electrónico)

SÁNCHEZ, M., y ORDÓÑEZ, A. Juicios mediáticos y presunción de inocencia. Málaga. La Ley S. A., N. . 57, 2016. 
SUÁREZ, G. "La responsabilidad periodística, límite legítimo al ejercicio profesional". Palabra Clave. vol. IX, N. ${ }^{\circ}$, 2006. (electrónico)

TISNÉS, J. "Principio de inocencia y medida de aseguramiento privativa de la libertad en Colombia. Un Estado constitucional de Derecho", Revista Ratio Juris. vol. VI, N. ${ }^{\circ}$ 13, 2011. (electrónico)

VALENCIA, C. "Juicios paralelos en Colombia y la imposibilidad de aplicar el principio de presunción de inocencia", Analecta Política. vol. VI, N. 11, 2016. (electrónico)

VEGAS, J. Presunción de inocencia y prueba en el proceso penal. Madrid, La Ley S.A., 1993.

YON, R., y SÁNCHEZ, A. "Presunción de inocencia y Estado de Derecho", Revista de Derecho. N. ${ }^{\circ}$ 51, Editorial Temis, 2005. (electrónico)

ZARAGOZA, J. "Libertad de información y «juicios paralelos»: la doctrina del Consejo de Europa", Boletín del Ministerio de Justicia. Año 54, N. ${ }^{\circ}$ 1881, 2000. (electrónico) 